\title{
Sensory and Instrumental Methods of Meat Evaluation: A Review
}

\author{
Siraj Sh. Mohammed Adam \\ Animal Production Student (M.Sc), School of Animal and Range Sciences, Haramaya University, Haramaya, P. O. Box 138, Dire \\ Dawa, Ethiopia.
}

How to cite this paper: Siraj Sh. Mohammed Adam. (2021) Sensory and Instrumental Methods of Meat Evaluation: A Review. International Journal of Food Science and Agriculture, 5(4), 627-638. DOI: $10.26855 /$ ijfsa.2021.12.010

Received: September 15, 2021

Accepted: October 10, 2021

Published: November 12, 2021

*Corresponding author: Siraj Sh. Mohammed Adam, Animal Production Student (M.Sc), School of Animal and Range Sciences, Haramaya University, Haramaya, P. O. Box 138, Dire Dawa, Ethiopia.

Email: sirajmhd2021@gmail.com

\begin{abstract}
Meat is one of the most commonly consumed agricultural products because it provides proteins, minerals, and essential vitamins, all of which are important in human nutrition and health. Because of its high moisture content, meat is a perishable food product, raising concerns regarding its quality, stability, and safety. Sensory evaluation and instrumentation testing are two extensively used methods for monitoring meat quality attributes. This review summarizes some of the most important sensory and instrumental methods used in the development of new products, especially meat and meat products. Various types of sensory and instrumental analyses have been highlighted as important techniques in new product development for evaluating the quality and marketability of novel products. Furthermore, evaluating consumer attitudes, actions, and emotions to better understand the complicated consumer-product relationship is an important aspect of new developments. This review will help in a better understanding of these techniques and the selection of the most appropriate at various stages of new product development, with a focus on meat products.
\end{abstract}

\section{Keywords}

Meat Quality, Meat Safety, Sensory Analysis, Instrumental Analysis

\section{Introduction}

Due to its large content of high-quality protein, minerals, vitamins, and other nutrients, meat and meat products play an important role in the human diet and health [1]. However, the high perishability of such products necessitates the use of one or more conservation or processing procedures. As a result of an increasing number of recent safety issues and product issues, the meat industry has turned its attention to ensuring the quality and safety of raw and processed meat [2].

Furthermore, people are becoming more aware of food labels and paying greater attention to the quality of meat products [3]. As a result of these concerns, the meat industry has begun to redefine and revise standards for measuring and monitoring the quality and safety aspects of meat and meat products [4, 5]. The significance of meat production traceability, on the other hand, should be emphasized. The proper information must be shown on the product to inform the consumer and provide a true guarantee of desired attributes. Only consistent quality meat products can persuade consumers that they are of high quality and worth paying a high price for [6]. According to these authors, quality systems designed to ensure repeatability must be founded on accurate, timely, and effective examination of key quality factors that matter to consumers. Meanwhile, the meat processing industry's problems are commonly attributed to a lack of communication among meat processing chain actors, as well as a lack of consumer-focused regulation. As a result, the purpose of this review is to discuss some of the sensory and instrumental techniques that are used to analyze/evaluate meat and meat products. 


\section{Meat Quality Evaluation}

Meat quality evaluation can be defined as the determination of the characteristics required to assess the appropriateness of fresh or preserved meat without any deterioration within a specified period [7]. Color, flavor, and fragrance are the consumer's first perceptions of meat quality, and they have a direct impact on purchasing decisions. Water holding capacity (WHC), marbling, and Warner-Bratzler shear force (WBSF) test results are some of the physical characteristics [2]. Total viable content (TVC) and bacterial infection are two of the most important microbiological criteria in determining the quality and safety of meat. Chemical properties such as protein, moisture, and $\mathrm{pH}$ provide information on the composition and nutritional content of meat. All of these criteria contribute to the defining of meat quality attributes.

As a result, reliable technology is required to monitor and assess meat qualities before the sale from the standpoint of meat quality and safety $[8,9]$. To assess meat quality and safety, a variety of well-established analytical methods have been used. Sensory examination, chemical analysis, and instrumentation tests are examples of these methods [10]. SE involves manually determining meat quality based on characteristics such as tenderness, flavor, and color. One advantage of SE is that it produces high-quality information quickly [11]. However, this method is time-consuming, subjective, and highly dependent on the inspector's level of weariness.

Instrumentation methods, such as WBSF, a $\mathrm{pH}$ meter, and meat colorimeters, are used to examine the texture or freshness of meat $[11,12]$. When compared to subjective sensory evaluation, these procedures are regarded as valid, consistent, accurate, and dependable [8]. However, there are numerous disadvantages to using these methods to identify meat quality, including the fact that they are destructive, involve sophisticated sample preparation, require highly skilled operators, are inappropriate for on/in-line monitoring, and take a long time to process [13, 14].

\subsection{Sensory Evaluation of Meat}

Sensory analysis is a scientific specialty used to assess, study, and explain the response of the particularities of food that are observed and interpreted by the panelists using their senses of sight, smell, taste, touch, and hearing [15]. Because of the human factor, sensory analysis has a subjective connotation. In general, evidence gathered from human perception reveals a large deal of variation among participants. Many of the responses from individuals are incomprehensible in this type of study. As a result, to restrict the test's subjectivity, the conditions surrounding its development must be carefully monitored. The sensory evaluation results will be more objective as a result of this [16].

To address these variations and improve the accuracy of the analysis, many factors must be considered: adequate personnel selection, training, preparation, and information to the panel, the location where the sensorial analysis will be performed (tasting room with individual test booths), sample preparation and serving, sample labeling with random numbers, and so on [17]. Furthermore, because of the possibility for variability, effective data analysis and interpretation are critical components of sensory techniques. As a result, a major aspect of sensory testing is evaluating the results and conducting statistical analysis. This requires significant statistical expertise in both quantitative and qualitative sectors [18].

Consumers employ a variety of measurable quality factors to decide their desire when purchasing meat. Color, textural patterns, visual appeal, and odor are all important factors for customers when selecting fresh meat [15]. These variables are linked to physical and chemical features such as marbling, protein content, and WHC in some way. These observable characteristics are valuable and effective indications of cooked product tenderness, hardness, or juiciness. Gender, species, and maturity level are among the many markers used to determine the quality of raw meat.

The results of most previous studies did not correspond significantly to the chemical or microbiological changes of the meat in some studies where sensory evaluation for meat quality evaluation was used, and the results found in most previous studies did not correspond significantly to the chemical or microbiological changes of the meat [2]. When using sensory evaluation to measure microbiological features, the inaccuracy can sometimes be too significant, resulting in a false positive or false negative. Due to issues such as human error, sensory evaluation has a much broader confidence interval, which can cause serious difficulties. This example demonstrates that sensory evaluation is not dependable and insufficient to provide a thorough understanding of meat quality. Sensory evaluation is neither viable nor scalable for use in a contemporary meat processing facility for a variety of reasons, including cost, time limits, and subjectivity [19].

\subsubsection{Sensory Evaluation Methods}

At first, quality control of industrial products was handled by a single individual or a small group of employees. They would use precarious sensory testing to determine whether a production method is good or not, as well as the quality of the end product. The tests were gradually replaced by more disciplined and directed tests that were more quantitative and exact, more accurate, less dangerous, and did not require segmentation [20]. Sensory analysis is divided into two categories: analytical and emotional. Analytical tests, such as discriminating and descriptive evaluations, attempt to 
describe and distinguish items. Affective tests, on the other hand, attempt to assess product acceptance and are divided into preference and hedonic tests [15].

\section{a) Discriminative Testing}

These tests are used to see if there is a difference between the two food products [21]. For a simple choice, panelists should be knowledgeable about the product in question. Each participant must select one meal item from a list of options. Discriminative tests may be utilized for a variety of applications in the future. It is advised that 10-50 panelists participate in these examinations. The triangle test, duo-trio test, and paired-comparison test are all discriminative tests.

Triangular Test: When measuring the overall difference between two products, three samples are usually used in this test. Two of the three samples are comparable, but the third is different. Individual three-digit numbers must be assigned to the samples. The taster must choose a sample that is distinct from the rest. In these tests, the chances of accurately selecting the appropriate sample are higher. Because the procedure is prone to panelist fatigue, it is recommended that no more than six samples be reviewed in one testing session. Fewer tasters are required for the tests; at least 4-8 tasters are regarded as sufficient for single testing [16, 21].

Duo-Trio Tests: This decides whether or not two samples have a sensory difference. A reference sample and two test samples are always present; one of the test samples is identical to the reference, while the other is the test sample [22]. Members of the panel must identify the sample that is similar to the reference sample. When comparing unknown differences among samples, duo-trio tests are occasionally used instead of triangle testing, but they are regarded as less efficient than triangle tests. It is suggested that at least 7-10 assessors be used [16, 23].

Paired Comparison Tests: These are used when there is a known discrepancy in the chemical composition of the sample that necessitates sensory evaluation. Each panelist is given two different coded samples at the same time, and the aim is to identify the sample that is regarded to be superior in the specified sensory attribute [23]. Tasters are asked to compare the samples without determining the extent of the difference, such as "are the two samples identical or different?" or "which of the two samples is sugary?" The paired comparison test is less time-consuming than the triangle test and is typically used for highly flavorful or complex items. In this test, at least 7-10 panelists (duo-trio) are recommended [16, 23].

\section{b) Descriptive Tests}

Sensory qualities of foods are ranked in order of appearance in these tests, and relative intensities are assigned [20]. They provide more complete profiles of a product by recognizing and quantifying the product's many attributes. When compared to discriminative tests, descriptive tests are more extensive and sophisticated. They serve as a foundation for mapping product similarities and differences, as well as determining which sensory features are crucial to acceptability. It is usually carried out by 6 to 15 well-chosen and qualified panelists. Panelists are trained to evaluate products in the same way that any instrument would. Free Choice Profile (FCP), Quantitative Descriptive Analysis (QDA), Flavor Profile Analysis (FPA), Texture Profile Analysis (TPF), and Time Intensity Analysis (TIA) are examples of descriptive testing [24].

Free Choice Profile: There is no prior training for the panelists in this procedure, and each judge chooses his or her own set of criteria to classify the product. The judge should be regularly trained, and the answer should be computerized, before a time-intensity curve for the specified attribute may be obtained. The curve's maximum intensity, the point at which maximum is reached, and the first point at which no more perception occurs are all investigated using analysis of variance [20].

Quantitative Descriptive Analysis: This is a non-technical survey of sensory terms for a product generated by trained sensory panelists. The proportional differences between the samples are usually agreed upon by trained judges [25]. The objective of QDA and FCP is the same: to determine the intensity of all product features as well as to define the whole sensory profile.

Flavor Profile Analysis: This is important for determining the taste and odor of a sample. It is a method that creates a written record of a product's noticeable fragrance, flavor, and taste components. Individual aromas and flavors are described by panelists in the order in which they are perceived, and a consistent grading system is assigned. Typically, 4-6 panelists are recommended. They assess the product individually and write down their impressions in terms of aroma, flavor, and taste. Finally, in an open discussion, the report is given to a panel leader [25].

Texture profile analysis: This method has been frequently used to evaluate solid and semisolid foods. Typically, a panel of 6-9 people is assembled; textural qualities and other evaluation techniques are agreed upon by all panel members before the evaluation of the products in question [26, 27]. TPA is useful for evaluating food texture quickly, which is generally done by humans. Liquid samples that cannot hold their shape yet flow under gravity are poured into a cup and compressed homogenously in some tests. The parameters acquired from uniaxial compression, namely hardness, cohesiveness, and adhesiveness, are then analyzed without regard to their physical meaning [28]. 
Time Intensity Analysis: This is used to calculate the rate at which the intensity of defined characteristics changes over time. Its primary function is to calculate the intensity of any descriptor term in a product over time. The descriptive sensory tests TIA and FCP are commonly employed in scientific studies and by food industries [29].

c) Affective/Consumer Acceptance Tests

Subjective methods are another name for affective methods. These are quite beneficial for determining whether or not a food is acceptable or desired (which product is liked or preferred). Normally, a significant number of people must answer (50-150 panelists considered adequate). Panelists are not trained but are chosen based on previous product use, socioeconomic status, and geographic location [30].

Preference Ranking: Three or more samples are rank-ordered in this method, with one sample being favored over the others. This type of test collects data on people's preferences for a product and determines how different samples differ based on a single differentiating trait. Panelists are asked to rank the coded samples according to their preferences in consumer analysis [31].

Hedonic Rating Scale: This is one of the most extensively used sensory evaluation methods for determining how much people like food [16]. The 9-point Hedonic scale, 7-point Hedonic scale, and 5-point Hedonic scale are all used in practice. The 9-point Hedonic scale ranges from "very like" to "extremely dislike". Table 1 summarizes what type of sensory assessment methodology to use based on the questions you want to answer.

Table 1. Summary of Sensory Evaluation Methods and Their Related Questions

\begin{tabular}{|c|c|c|}
\hline Question & Method & Sub-types \\
\hline Are products different? & Discrimination test & $\begin{array}{l}\text {-Triangle test } \\
\text {-Duo-trio test } \\
\text {-Paired comparison test }\end{array}$ \\
\hline $\begin{array}{l}\text { If products are different, how are they } \\
\text { different? }\end{array}$ & Descriptive tests & $\begin{array}{l}\text {-Quantitative descriptive analysis } \\
\text {-Free choice profile } \\
\text {-Time-intensity analysis } \\
\text {-Flavor profile analysis } \\
\text {-Texture profile analysis }\end{array}$ \\
\hline $\begin{array}{c}\text { What is the acceptability of a product? Is } \\
\text { one product preferred over another? }\end{array}$ & Affective/Acceptance & $\begin{array}{l}\text {-Hedonic rating scale (5- Point, 7-Point and 9-Point He- } \\
\text { donic scale) } \\
\text {-Preference ranking }\end{array}$ \\
\hline
\end{tabular}

Source: Mihafu, et al. (2020).

\section{Recent Advanced Meat Evaluation Methods (Instrumental)}

The demand for the use of nondestructive procedures in evaluating meat quality and safety qualities has increased due to the rapid rise in public knowledge and concern for superior meat quality [2]. According to the literature reviewed, the most sophisticated methods for evaluating meat quality that is based on imaging and the electromagnetic spectrum meet the demand criteria of being quick, nondestructive, and suitable for online/in-line monitoring. The following techniques are discussed in this section: e-nose, CV, spectroscopy, HSI, and MSI. These technologies were chosen because of their ability to be scaled up to industrial levels [14, 32].

\subsection{Electronic Nose}

E-nose is an artificial olfactory system that mimics the human olfactory system [33]. It is a tool for analyzing food aromas and identifying volatile chemicals. It can also analyze simple or complicated gases, vapors, or scents qualitatively and quantitatively [14]. The E-nose is made up of a network of sensors that generate electrical impulses in reaction to volatile substances in a gaseous sample [34]. Sample delivery, detection, and computing are the three main systems. A sample is collected via the sample delivery system, which is then injected into the detecting system. In practice, an air sample is drawn through a tube into a tiny chamber holding the electronic sensor array by a pump. A group of sensors perceives and responds to the compounds in the detection system, and the response is recorded by an electrical interface [35]. Ramirez et al. [36] used a pattern recognition algorithm to process the collected signals, followed by classification to classify the unknown gas. The studies summarized in Table 2 showed that E-nose technology has been used successfully in the detection of meat quality and can be used as a promising technique for rapid evaluation of meat quality and safety, as well as for the detection of adulterations in meat. E-nose techniques achieved satisfactory results with an average precision of almost $90 \%$ using appropriate pattern recognition techniques for data analysis [37]. These 
results suggest that e-nose can be used to detect meat quality and safety, as well as to detect harmful compounds.

In general, the odor of the sample stimulus creates a unique fingerprint that can be recognized by the e-nose system's nonspecific sensors. These fingerprints are collected and stored in a database that is used to categorize target smells [14]. Signal analyses of e-nose data are typically complicated, necessitating the use of multivariate data analysis tools and particular pattern recognition methods to predict signal response using chemical or physical reference factors [34, 38]. To treat the complicated e-nose data and extract useful information, methods such as principal component regression (PCR), partial least squares (PLS), or artificial neural network (ANN) can be applied.

Table 2. Some Previous Studies that Used E-Nose Technique for Meat Quality and Safety Detection

\begin{tabular}{|c|c|c|c|c|c|}
\hline $\begin{array}{l}\text { Meat } \\
\text { type }\end{array}$ & Quality attribute & E-nose type & $\begin{array}{l}\text { Statistical } \\
\text { approach }\end{array}$ & $\begin{array}{l}\text { Significant } \\
\text { results }\end{array}$ & Reference \\
\hline Pork & $\begin{array}{l}\text { Color, moisture content, } \\
\text { redox potential, } \mathrm{pH}\end{array}$ & $\begin{array}{c}\text { The Food } \\
\text { Sniffer R@ } \\
\text { (FS) }\end{array}$ & PCA & $\begin{array}{l}\text { CP } 1(71.13 \%) \text { and } \\
\quad \text { CP2 }(12.57 \%)\end{array}$ & [36] \\
\hline Beef & $\begin{array}{l}\text { Microbial } \\
\text { component }\end{array}$ & Sensor array & $\mathrm{kNN}$ & $\begin{array}{c}3.64 \%, 86 \% \text {, and } \\
85.5 \%\end{array}$ & [37] \\
\hline Poultry & Odor & Sensor array & $\begin{array}{l}\text { kNN, Classification tree, SVM, } \\
\text { Naive Bayes (NB), Random forest }\end{array}$ & $53 \%-79 \%$ & [35] \\
\hline Chicken & VFA & MOS system & - & $\mathrm{R} 2=0.89$ & [33] \\
\hline
\end{tabular}

Note: BP-ANN, backpropagation artificial neural network; BPNN, backpropagation neural network; GRNN, general regression neural network; kNN, k-nearest neighbors; LDA, linear discriminant analysis; MOS, metal oxide sensor; PCA, principal component analysis; NB, naive Bayes; PLS, partial least squares; SLDA, supervised latent Dirichlet allocation; SVM, support vector machine; TVB-N, total volatile basic nitrogen; VFA, volatile fatty acids.

E-nose has proven to be a viable approach for detecting meat freshness, and it has a lot of potential in quality control and assurance. It has several benefits, including high sensitivity, quick result classification, the capacity to detect dangerous or harmful gases, and a broad range of operating circumstances. The e-nose also has a cheap per-sample cost and requires little to no specific sample preparation [39-41]. Based on a surface acoustic wave sensor, Nurjuliana et al. [42] used e-nose to evaluate pork quality. The researchers discovered a two-dimensional olfactory image that can distinguish different samples qualitatively in a short amount of time (15 s). Similarly, Jia et al. [14] investigated ham sensory evaluation using e-nose. With an R2 of 1.0, they discovered that the PCA model had the highest effective extraction and precision in predicting sensory quality.

Various findings of the usage of e-nose in meat quality and safety detection indicated that e-nose technology has been successfully implemented in meat quality detection and can be used as a promising tool to quickly evaluate meat quality and safety, as well as to detect meat adulteration [2]. With the use of proper pattern recognition algorithms for data processing, the e-nose procedures achieved satisfactory results of almost $90 \%$ average accuracy [41].

\subsection{Computer Vision}

$\mathrm{CV}$ is a new technique that is being used to detect and evaluate external quality features in a variety of agricultural products [43, 44]. CV gathers and analyzes spatial data from sample digital photographs, such as color, size, and surface structure [45]. This system consists of a camera, a lighting chamber, a light source, a computer, and software applications. Reflectance, absorption, and transmission are the three detecting techniques used by CV [46]. Many factors influence the light's response in a measured object, including the incident light's wavelength and penetration, the object's physical and chemical qualities, and the sample's refraction index [43]. As a result, having adequate light on the object's surface can help the camera detect surface features by improving contrast and edge recognition.

Image processing and image analysis (scene/object recognition) are the two major components of CV data analysis. Many different methods were used to measure and evaluate images in the reviewed literature, including correlation, segmentation, and identification of regions of interest, feature extraction, and classification. Partial least squares regression, k-means clustering, stepwise multiple regression, support vector machine, linear discriminant analysis, and analysis of variance are examples of these methodologies [47].

Because of its nondestructive and adaptable nature, $\mathrm{CV}$ techniques have shown their potential in the meat industry for the detection of surface quality characteristics and color classification [8, 48]. CV approaches were used by Zapotoczny et al. [49] to analyze the quality of pork and poultry. The correlation between visual textures and chemical compositions 
was discovered to be between 0.7 and 0.92 . The studies presented in Table 3 showing different ways to use CV to assess meat quality. These results show that $\mathrm{CV}$ can be used as a non-destructive tool to evaluate the quality and safety of meat in production lines; however, there is a need to significantly improve the ability to detect subtle differences in color or texture, which are equally important for overall meat quality certification.

Table 3. Some of Previous Studies that Used CV Technique to Detect Meat Quality and Safety

\begin{tabular}{cccccc}
\hline Meat type & Quality attribute & Color space & Statistical approach & $\begin{array}{c}\text { Significant } \\
\text { results }\end{array}$ & Reference \\
\hline Pork & Color & RGB, HSV & $\begin{array}{c}\text { Global thresholding, } \\
\text { k-meansclustering }\end{array}$ & R2 $=0.99$ & {$[47]$} \\
Chicken & Color & CIE L*a*b* & CV colorimeter & R2 $=0.99$ & {$[43]$} \\
Lamb & Marbling & RGB & MLP & $91 \%$ & {$[50]$} \\
Chicken & Freshness & $\begin{array}{c}\text { RGB, HSI, } \\
\text { L*a*b* }\end{array}$ & CV, GA-ANN, ANN & R2 $=0.99$ & {$[46]$} \\
Pork & Color, marbling & HSI, L*a*b* & SVM & $92.5 \%, 75 \%$ & {$[51]$} \\
Chicken & Sorting & RGB, HSV & PLSR, LDA, ANN & $93 \%$ & {$[52]$}
\end{tabular}

Note: ANN, artificial neural network; ANOVA, analysis of variance; CIE, Commission Internationale de l'Elcairage; CVs, computer visions; CVS, computer vision systems; GA-ANN, genetic algorithm-artificial neural network; HSI, hue, saturation, and intensity; HSV, hue, saturation, and value; IMF, intramuscular fat; L*a*,b*, lightness, redness, and yellowness; LDA, linear discriminant analysis; MLP, multilayer perceptron; ARTMAP, adaptive resonance theory map; PLS, partial least squares; PLSR, partial least squares regression; RGB, red, green, and blue; SVM, support vector machine.

\subsection{Spectroscopy Techniques}

Due to its advantages over many analysis methods, spectroscopy is regarded as one of the most promising nondestructive techniques [53]. A typical spectroscopic system has four parts: sampling devices, photodetector, light-isolating mechanisms, and light source. There are three types of data acquisition modes in spectroscopy: interactance, reflectance, and transmittance. The mode is determined by the detector and light source's respective positions. The wavelength passband is narrow in transmission mode and wide in reflectance mode, hence these modes have a direct impact on the wavelength passband.

For meat applications, four wavelength areas have been identified: fluorescence, visible (VIS), near-infrared (NIR), and mid-infrared (MIR). The American Society of Testing and Materials (ASTM) has quantified these multiple wavelength ranges, which include fluorescence wavelengths ranging from 100 to $400 \mathrm{~nm}$, VIS wavelengths ranging from 400 to $750 \mathrm{~nm}$, NIR wavelengths ranging from 780 to $2500 \mathrm{~nm}$, and MIR wavelengths ranging from 2,500 to 25,000 $\mathrm{nm}$ [54]. These areas represent some of the several modes in which a spectroscopic measurement procedure can work. Because variations in the absorption of incident light in the target regions of the electromagnetic spectrum differ depending on the composition of the region of interest [55].

Spectroscopy has been used to monitor and detect meat quality and microbiological contaminations in various research that have been published [56, 57, 14]. Shear force, TVC, IMF (intramuscular fat), TVB-N (total volatile basic nitrogen), and thiobarbituric acid reactive chemicals in beef; TVC and TVB-N in pork; and drip loss, moisture, water activity, TVB-N, and adenosine triphosphate in poultry are among these quality characteristics.

The interaction of chemical ingredients, basic vibrations, and stretching of molecules under electromagnetic radiation determines the reflectance qualities of meat in general (Khaled et al., 2018). Chemical ingredient differences can be used to create detailed fingerprints for detecting quality, such as the freshness of meat [58]. The molecular vibrations of chemical elements of meat are indicated by the spectrum information used in VIS and NIR reflectance techniques, particularly the overtones and combination bands of vibrational modes in the form of $\mathrm{C}-\mathrm{X}$, where $\mathrm{X}$ is nitrogen, oxygen, or carbon and $\mathrm{C}$ is carbon. The $\mathrm{X}-\mathrm{H}$ stretching region $(2,500-4,000 \mathrm{~nm})$, the triple bond region $(4,000-5,000 \mathrm{~nm})$, the double bond region (5,000-6,666 nm), and the fingerprint region $(6,666-25,000 \mathrm{~nm})$ are the four broad regions of MIR spectroscopy. It has been reported that MIR absorbance has come from only one sort of vibrational reaction, and its spectral peaks are exclusive to one form of organic bond.

Typical quantitative and qualitative spectroscopic data analysis required in many analyses is computationally expensive, ill-fitting, and susceptible to interference [53]. As indicated in Table 4, spectroscopy used to evaluate the quality and safety of meat. In the reviewed studies, VIS, NIR, MIR and fluorescence spectral ranges were used with a frequen- 
cy of $60 \%, 80 \%, 8 \%$ and $12 \%$, respectively [56]. The results show that VIS/NIR was used in about three-quarters of the studies revised, which can be partly explained by speed, lower start-up costs, and lower equipment complexity.

Table 4. Some of Previous Studies that Used Spectroscopy Technique to Detect Meat Quality and Safety

\begin{tabular}{|c|c|c|c|c|c|c|}
\hline Meat type & Quality attributes & $\begin{array}{l}\text { Spectroscopy } \\
\text { type }\end{array}$ & $\begin{array}{l}\text { Wavelength } \\
\text { range (nm) }\end{array}$ & $\begin{array}{l}\text { Statistical } \\
\text { approach }\end{array}$ & $\begin{array}{l}\text { Significant } \\
\text { results }\end{array}$ & Reference \\
\hline Chicken/poultry & Color, WHC, pH & NIR & $968-2,494$ & $\begin{array}{c}\text { Decision Trees, } \\
\text { SVM }\end{array}$ & $77.2 \%$ & {$[56]$} \\
\hline $\begin{array}{l}\text { Minced beef and } \\
\text { pork }\end{array}$ & Adulteration & VIS and NIR & $400-1,700$ & $\begin{array}{l}\text { LDA, PLSR, } \\
\text { SNV }\end{array}$ & $96 \%$ and $100 \%$ & [59] \\
\hline Beef & $\begin{array}{l}\mathrm{pH} \text {, color, cook } \\
\text { loss, drip loss }\end{array}$ & VIS and NIR & $350-2,500$ & PLS & $\begin{array}{c}\mathrm{R} 2 \\
\mathrm{CV}(0.91-0.96)\end{array}$ & {$[60]$} \\
\hline Beef, pork, lamb & $\begin{array}{l}\text { Characterize meat, } \\
\text { fat }\end{array}$ & NIR & $750-2,500$ & $\begin{array}{l}\text { MSC, SNV, } \\
\text { OSC, DOSC, } \\
\text { OWAVEC }\end{array}$ & $\begin{array}{c}\mathrm{R} 2 \\
\mathrm{CV}(0.62-0.96)\end{array}$ & {$[58]$} \\
\hline Pork & Quality attributes & MIR & $2,500-14,285$ & $\begin{array}{l}\text { Response } \\
\text { correction, } \\
\text { PLSR }\end{array}$ & - & {$[14]$} \\
\hline Beef & Shear value, IMF & VIS and NIR & $400-1,395$ & _ & $100 \%$ & {$[61]$} \\
\hline
\end{tabular}

Note: ANN, artificial neural network; DOSC, direct orthogonal signal correction; IMF, intramuscular fat; MSC, multiple scatter correction; NIR, near-infrared; OSC, orthogonal signal correction; OWAVEC, orthogonal wavelet correction; PCA, principal component analysis; SNV, standard normal variate; TBA, thiobarbituric acid; TBARS, thiobarbituric acid-reactive substances; TVB-N, total volatile basic nitrogen; TVC, total viable content; VBN, volatile basic nitrogen; RMSEP, root mean squared error of prediction; VIS, visible; WBSF, Warner-Bratzler shear force; WHC, water holding capacity.

\subsection{Hyperspectral Imaging System}

HSI is a relatively recent approach for nondestructively evaluating the quality of food products [3]. It combines image and spectroscopic technologies to simultaneously provide spatial and spectral information about a sample. HSI can detect a sample's external and internal quality features as a result of this integration [62]. In HSI, spatial and spectral information is used to characterize and identify a complex heterogeneous sample as well as a variety of multi-constituent surface and subsurface features. A light source, a lens, an imaging spectrograph, a camera, a sample holding platform, and an interfaced computer with sample stage and data analysis software are typical components of an HSI system.

In a three-dimensional hypercube $(\mathrm{x}, \mathrm{y})$, where $\mathrm{x}$ and $\mathrm{y}$ are spatial dimensions and is the spectral dimension, HSI gives a huge amount of information. Hypercube data can be seen in two ways: as a stack of images, each representing a different wavelength, or as the whole spectrum at each pixel. Hypercube analysis can be difficult since it often necessitates the use of chemometric models and statistical techniques. Furthermore, because hypercube data might have enormous dimensions and sizes, classification and prediction models developed with it will usually require dimensionality reduction [63]. Interference correction, dimensionality reduction, and feature extraction are some of the most often used approaches for preprocessing data from a hypercube [64].

The use of HSI in the meat sector to evaluate quality and safety qualities has the potential to increase consumer confidence in meat products, owing to the capacity to collect particular information on each piece of meat, which was previously impossible. Chemical composition, adulteration, sensory attribute prediction, contaminant detection, and bacterial deterioration can all benefit from the use of HIS [63]. Table 5 shows examples of many studies that have used HSI to evaluate different parameters in different types of meat (beef, pork, lamb, and chicken). The results of these studies showed that HSI in combination with chemometric techniques has the potential for a rapid and non-destructive evaluation of the safety and quality characteristics of meat. Studies reviewed have shown HSI techniques to be $38 \%$ to $99 \%$ accurate, with VIS/NIR with line scanning being the most widely used approach [65]. Despite the various advantages of this technique, there are some limitations when implementing it directly in an online system, for example; if the number of acquired/processed wavelengths can be restricted, this will significantly reduce the amount of data. Most industrial applications attempt to select optimal wavelengths/characteristics to ensure the fastest feedback from the resulting multispectral model [62]. 
Table 5. Some of Previous Studies that Used HSI Technique to Detect Meat Quality and Safety

\begin{tabular}{|c|c|c|c|c|c|c|}
\hline $\begin{array}{l}\text { Meat } \\
\text { type }\end{array}$ & Quality attributes & $\begin{array}{l}\text { Wavelength } \\
\text { range (nm) }\end{array}$ & $\begin{array}{c}\text { Image } \\
\text { size/resolution }\end{array}$ & $\begin{array}{l}\text { Statistical ap- } \\
\text { proach }\end{array}$ & $\begin{array}{l}\text { Significant } \\
\text { results }\end{array}$ & Reference \\
\hline Beef & Tenderness & $400-1,000$ & $\begin{array}{c}1,312 \times 10,820.16 \\
\mathrm{~mm}\end{array}$ & $\begin{array}{l}\text { PCA, FLD, } \\
\text { SVM, DT }\end{array}$ & $86.7 \%$ & {$[66]$} \\
\hline Pork & TVC & $400-1,100$ & $\begin{array}{c}1,376 \times 10,402.8 \\
\mathrm{~nm}\end{array}$ & MLR & $\mathrm{R} \mathrm{v}=0.38-0.94$ & {$[67]$} \\
\hline Pork & $\begin{array}{l}\text { Water activity, pH, } \\
\text { hardness, TBA }\end{array}$ & $380-1,000$ & $5 \mathrm{~nm}$ & DFA, QDI, PLS & $\mathrm{R} 2=0.96-0.99$ & [68] \\
\hline Chicken & TVB-N & $430-960$ & $200 \times 200$ & $\begin{array}{l}\text { SNV, ACO, } \\
\text { PCA, BPANN }\end{array}$ & $\mathrm{R} p=0.88$ & [69] \\
\hline Mutton & TVB-N, TAC & $400-1,000$ & $2.8 \mathrm{~nm}$ & BPNN & $94 \%$ & {$[70]$} \\
\hline Chicken & Tenderness & $400-1,000$ & $688 \times 500$ & PCA, PLS-DA & $\begin{array}{l}0.84(\mathrm{FR}) \\
0.92(\mathrm{SR})\end{array}$ & {$[71]$} \\
\hline
\end{tabular}

Note: ACO, ant colony optimization; BPANN, back propagation artificial neural networks; BPNN, back propagation neural network; DFA, discriminant factor analysis; DT, decision tree; FLD, Fisher's linear discriminant; MLR, multiple linear regression; FR, full range; MLR, multiple linear regression; PCA, principal component analysis; PLS, partial least squares; PLS-DA, partial least squares-discriminant analysis; PLSR, partial least squares regression; QDI, quality deterioration index; R p, correlation coefficient of prediction set; R v, correlation coefficient; SMLR, sparse multinomial logistic regression; SVM, support vector machine; PNN, probabilistic neural network; PPC, psychrotrophic plate count; SMLR, stepwise multiple linear regression; SR, selected range; SVR, support vector regression; TAC, total aerobic plate count; TBA, thiobarbituric acid; TVB-N, total volatile basic nitrogen; TVC, total viable count.

\subsection{Multispectral Imaging}

MSI is a cutting-edge technology that has been used to inspect raw and processed meat. It is a reformation of HSI, with the difference that it uses an optimized subset of the wavelengths utilized in HSI, allowing it to work with substantially fewer data [72, 73]. MSI usually uses three to fifteen separate, noncontiguous, and unevenly spaced wavelengths [65]. It can achieve faster identification and detection than line-scan HSI since it has both greater quality and a less amount of data to analyze [74]. The use of shorter wavelengths also provides for cost savings in hardware and optical sensors [73]. As a result, if HSI and MSI met the same performance standards, MSI would be chosen for industrial systems implementation. MSI captures three-dimensional images (a one-dimensional spectrum $[\lambda]$ at every two-dimensional pixel [x and $y]$ ) that contain heterogeneous information describing meat physicochemical properties, similar to HIS [72]. To capture spectral information together, a variety of wavelength light sources are employed [75].

MSI has mostly been used in the meat industry to evaluate product quality and safety [76]-78] (see Table 6). Adulteration detection in chicken breast fillets Ropodi et al. [78], heme and non-heme iron content prediction in pig sausageMa et al. [72] and frozen minced beef quality evaluation are examples of specific applications [79].

Table 6. Some of Previous Studies that Used MSI Technique to Detect Meat Quality and Safety

\begin{tabular}{|c|c|c|c|c|c|c|}
\hline $\begin{array}{l}\text { Meat } \\
\text { type }\end{array}$ & Quality attributes & $\begin{array}{l}\text { Spectral } \\
\text { bands }\end{array}$ & $\begin{array}{l}\text { Wavelength } \\
\text { range }(\mathrm{nm})\end{array}$ & Statistical approach & $\begin{array}{l}\text { Significant } \\
\text { results }\end{array}$ & Reference \\
\hline Beef & $\begin{array}{l}\text { Minced beef and } \\
\text { horsemeat }\end{array}$ & 18 & $405-970$ & PLS-DA, RF, SVM & $\begin{array}{l}100 \%, \\
96.62 \%\end{array}$ & {$[77]$} \\
\hline Pork & bone fragments & 19 & $405-970$ & $\begin{array}{c}\text { SPA, LDA, } \\
\text { PCA-LDA, PLS-DA, }\end{array}$ & $\begin{array}{l}100 \% \text { for } \\
\text { test set }\end{array}$ & {$[80]$} \\
\hline Beef & TVC & 18 & $405-970$ & $\begin{array}{l}\text { OLS-R, SL-R, } \\
\text { PLS-R, PCR, SVR, } \\
\text { RF, kNN }\end{array}$ & $98.6 \%$ & [77] \\
\hline Beef & Frozen-then-thawed & 18 & $405-970$ & PLS-DA, SVM & $100 \%$ & {$[78]$} \\
\hline Chicken & $\begin{array}{l}\text { TVC, Pseudomonas } \\
\text { spp }\end{array}$ & 18 & $407-970$ & PLS-R, ANN & $90.4 \%$ & [79] \\
\hline Beef & Water-injected & 19 & $405-970$ & PLS-R & $94.6 \%$ & {$[75]$} \\
\hline
\end{tabular}

Note: ANN, artificial neural networks; kNN, k-nearest neighbors; LDA, linear discriminant analysis; OLS-R, ordinary least squares regression; PCA-LDA, principal component analysis-linear discriminant analysis; PCR, principal component regression; PLS-DA, partial least squares discriminant analysis; PLS-R, partial least square regression; RF, random forest; SL-R, stepwise linear regression; SPA, successive projection algorithm; SVM, support vector machine; SVR, support vector regression; TVC, total viable counts. 


\section{Summary}

In the meat industry, sensory evaluation is used to assess the conformity of raw materials and finished products to sensory specifications. When used appropriately, sensory science can provide information that no other instrument can: a complete description of how a food item is perceived by the human senses and/or how much it is enjoyed. It is critical to examine the scope of any sensory test as well as effective sensory practice. For bench-top testing and quality control of changed products, instrumented techniques that can properly assess textural changes and are validated by sensory methods are needed. In the meat/food processing sectors, integrating instrumental procedures with sensory evaluation is extremely valuable because no one method is universally applicable. The conclusion must be that it is critical to be aware of the measurement's objective and how to select methods based on that need.

\section{Acknowledgements}

I would like express my deepest gratitude to Dr. Yesihak Yusuf for his suggestions, comments and advice. I also thanks my friends who giving information, guidance, comments and suggestions.

\section{References}

[1] A. Hassoun, A. Aït-Kaddour, A. Sahar, and D. Cozzolino. (2021). Monitoring Thermal Treatments Applied to Meat Using Traditional Methods and Spectroscopic Techniques: a Review of Advances over the Last Decade. Food Bioprocess Technol., vol. 14, no. 2, pp. 195-208, doi: 10.1007/s11947-020-02510-0.

[2] A. Y. Khaled, C. A. Parrish, and A. Adedeji. (2021). Emerging nondestructive approaches for meat quality and safety evaluation-A review. Compr. Rev. Food Sci. Food Saf., vol. 20, no. 4, pp. 3438-3463, doi: 10.1111/1541-4337.12781.

[3] M. Kamruzzaman, Y. Makino, and S. Oshita. (2016). Rapid and non-destructive detection of chicken adulteration in minced beef using visible near-infrared hyperspectral imaging and machine learning. J. Food Eng., vol. 170, pp. 8-15, doi: 10.1016/j.jfoodeng.2015.08.023.

[4] S. Grassi, E. Casiraghi, and C. Alamprese. (2018). Handheld NIR device: A non-targeted approach to assess authenticity of fish fillets and patties, vol. 243.

[5] A. López-maestresalas. (2018). Detection of minced lamb and beef fraud using NIR spectroscopy, doi: 10.1016/j.foodcont.2018.12.003.

[6] G. P. and A. W. Dominika Guzek, Dominika Głąbska, and Ewelina Pogorzelska. (2013). Instrumental Texture Measurement of Meat in a Laboratory Research and on a Production Line, Adv. Sci. Technol.-Res. J., vol. 7, no. 19, pp. 5-11, doi: $10.5604 / 20804075.1062329$.

[7] M. O. Soodabeh Fatahia and Y. M. Amin Taheri-Garavanda. (2019). Meat quality evaluation based on computer vision technique: A review, Meat Sci., vol. 156, no. June, pp. 183-195, doi: 10.1016/j.meatsci.2019.06.002.

[8] Y. Peng and S. Dhakal. (2015). Optical methods and techniques for meat quality inspection, Trans. ASABE, vol. 58, no. 5, pp. 1371-1386, doi: 10.13031/trans.58.11004.

[9] Z. Xiong, A. Xie, D. W. Sun, X. A. Zeng, and D. Liu. (2015). Applications of Hyperspectral Imaging in Chicken Meat Safety and Quality Detection and Evaluation: A Review, Crit. Rev. Food Sci. Nutr., vol. 55, no. 9, pp. 1287-1301, doi: 10.1080/10408398.2013.834875.

[10] D. Du, J. Wang, B. Wang, L. Zhu, and X. Hong. (2019). Ripeness prediction of postharvest Kiwifruit using a MOS E-nose combined with chemometrics, Sensors (Switzerland), vol. 19, no. 2, doi: 10.3390/s19020419.

[11] J. Sujiwo, H. J. Kim, S. O. Song, and A. Jang. (2019). Relationship between quality and freshness traits and torrymeter value of beef loin during cold storage, Meat Sci., vol. 149, pp. 120-125, doi: 10.1016/j.meatsci.2018.11.017.

[12] Z. F. Bhat, J. D. Morton, S. L. Mason, and A. E. D. A. Bekhit. (2019). Does pulsed electric field have a potential to improve the quality of beef from older animals and how? Innov. Food Sci. Emerg. Technol., vol. 56, no. April, p. 102194, doi: 10.1016/j.ifset.2019.102194.

[13] P. Pophiwa, E. C. Webb, and L. Frylinck. (2020). A review of factors affecting goat meat quality and mitigating strategies, Small Rumin. Res., vol. 183, p. 106035, doi: 10.1016/j.smallrumres.2019.106035.

[14] W. Jia, G. Liang, Y. Wang, and J. Wang. (2018). Electronic Noses as a Powerful Tool for Assessing Meat Quality: a Mini Review, Food Anal. Methods, vol. 11, no. 10, pp. 2916-2924, doi: 10.1007/s12161-018-1283-1.

[15] C. Ruiz-capillas, A. M. Herrero, T. Pintado, and G. Delgado-pando. (2021). Sensory Analysis and Consumer Research in New Meat Products Development.

[16] H. T. Lawless and H. Heymann. (2010). Sensory evaluation of food: principles of good practice.

[17] O. Segun. (2007). Sensory Evaluation Techniques, 18th Annu. IAOM Conf. (MEA Dist. Muscat-Oman.

[18] G. Luciano and T. Næs. (2009). Interpreting sensory data by combining principal component analysis and analysis of variance, Food Qual. Prefer., vol. 20, no. 3, pp. 167-175, doi: 10.1016/j.foodqual.2008.08.003.

[19] K. Verplanken, J. Wauters, V. Vercruysse, M. Aluwé, and L. Vanhaecke. (2017). Sensory evaluation of boar-taint-containing minced meat, dry-cured ham and dry fermented sausage by a trained expert panel and consumers, Food Chem., vol. 233, pp. 247-255, doi: 10.1016/j.foodchem.2017.04.105. 
[20] F. D. Mihafu, J. Y. Issa, and M. W. Kamiyango. (2020). Implication of sensory evaluation and quality assessment in food product development: A review, Curr. Res. Nutr. Food Sci., vol. 8, no. 3, pp. 690-702, doi: 10.12944/CRNFSJ.8.3.03.

[21] D. Singh-Ackbarali and R. Maharaj. (2014). Sensory Evaluation as a Tool in Determining Acceptability of Innovative Products Developed by Undergraduate Students in Food Science and Technology at The University of Trinidad and Tobago, J. Curric. Teach., vol. 3, no. 1, pp. 10-27, doi: 10.5430/jct.v3n1p10.

[22] H. S. Lee and K. O. Kim. (2008). Difference test sensitivity: Comparison of three versions of the duo-trio method requiring different memory schemes and taste sequences, Food Qual. Prefer., vol. 19, no. 1, pp. 97-102, doi: 10.1016/j.foodqual.2007.07.004.

[23] M. Y. B. Adjei. (2017). Applications and Limitations of Discrimination Testing. Elsevier Ltd.

[24] F. Silva, et al. (2020). CATA vs FCP for a rapid descriptive analysis in sensory characterization of fish, J. Sens. Stud., vol. 35, no. 6, doi: 10.1111/joss.12605.

[25] A. C. Bovell-Benjamin and J. X. Guinard. (2003). Novel Approaches and Application of Contemporary Sensory Evaluation Practices in Iron Fortification Programs, Crit. Rev. Food Sci. Nutr., vol. 43, no. 4, pp. 379-400, doi: 10.1080/10408690390826563.

[26] S. Jain, L. L. Rai, and S. S. Ahlawat. (2020). Proximate compositional, texture profile and colour profile analysis of cottage cheeses prepared using milk clotting enzymes extracted from mustard and sunflower oilseed cakes, Pharma Innov. J., vol. 9, no. 2, pp. 277-281, [Online]. Available: http://www.thepharmajournal.com.

[27] K. Kohyama. (2020). Food Texture-Sensory Evaluation and Instrumental Measurement, Textural Charact. World Foods, vol. 1, no. Kohyama 2015, pp. 1-13, doi: 10.1002/9781119430902.ch1.

[28] K. Nishinari, K. Kohyama, H. Kumagai, T. Funami, and M. C. Bourne. (2013). Parameters of texture profile analysis, Food Sci. Technol. Res., vol. 19, no. 3, pp. 519-521, doi: 10.3136/fstr.19.519.

[29] A. G. Cruz, et al. (2010). Sensory analysis: Relevance for prebiotic, probiotic, and synbiotic product development, Compr. Rev. Food Sci. Food Saf., vol. 9, no. 4, pp. 358-373, doi: 10.1111/j.1541-4337.2010.00115.x.

[30] A. Mayssara A. (2014). Abo Hassanin Supervised, Sensory Evaluation Techniques.

[31] K. A. Hein, S. R. Jaeger, B. Tom Carr, and C. M. Delahunty. (2008). Comparison of five common acceptance and preference methods, Food Qual. Prefer., vol. 19, no. 7, pp. 651-661, doi: 10.1016/j.foodqual.2008.06.001.

[32] W. Lan, B. Jaillais, A. Leca, C. M. G. C. Renard, and S. Bureau. (2020). A new application of NIR spectroscopy to describe and predict purees quality from the non-destructive apple measurements, Food Chem., vol. 310, p. 125944, doi: 10.1016/j.foodchem.2019.125944.

[33] R. Edita, et al. (2018). Rapid evaluation of fresh chicken meat quality by electronic nose, Czech J. Food Sci., vol. 36, no. 5, pp. 420-426, doi: 10.17221/419/2017-cjfs.

[34] K. Timsorn, T. Thoopboochagorn, N. Lertwattanasakul, and C. Wongchoosuk. (2016). Evaluation of bacterial population on chicken meats using a briefcase electronic nose, Biosyst. Eng., vol. 151, pp. 116-125, doi: 10.1016/j.biosystemseng.2016.09.005.

[35] W. Wojnowski, T. Majchrzak, T. Dymerski, J. Gębicki, and J. Namieśnik. (2017). Poultry meat freshness evaluation using electronic nose technology and ultra-fast gas chromatography, Monatshefte fur Chemie, vol. 148, no. 9, pp. 1631-1637, doi: 10.1007/s00706-017-1969-x.

[36] H. L. Ramírez, A. Soriano, S. Gómez, J. U. Iranzo, and A. I. Briones. (2018). Evaluation of the Food Sniffer electronic nose for assessing the shelf life of fresh pork meat compared to physicochemical measurements of meat quality, Eur. Food Res. Technol., vol. 244, no. 6, pp. 1047-1055, doi: 10.1007/s00217-017-3021-0.

[37] D. R. Wijaya, R. Sarno, E. Zulaika, and S. I. Sabila. (2017). Development of mobile electronic nose for beef quality monitoring, Procedia Comput. Sci., vol. 124, pp. 728-735, doi: 10.1016/j.procs.2017.12.211.

[38] M. Xu, J. Wang, and L. Zhu. (2018). The qualitative and quantitative assessment of tea quality based on E-nose, E-tongue and E-eye combined with chemometrics, Food Chem., vol. 289, no. pp. 482-489, 2019, doi: 10.1016/j.foodchem.2019.03.080.

[39] A. Gliszczyńska-Świgło and J. Chmielewski. (2017). Electronic Nose as a Tool for Monitoring the Authenticity of Food. A Review, Food Anal. Methods, vol. 10, no. 6, pp. 1800-1816, doi: 10.1007/s12161-016-0739-4.

[40] S. Kiani, S. Minaei, and M. Ghasemi-Varnamkhasti. (2016). A portable electronic nose as an expert system for aroma-based classification of saffron, Chemom. Intell. Lab. Syst., vol. 156, pp. 148-156, doi: 10.1016/j.chemolab.2016.05.013.

[41] A. Sanaeifar, H. ZakiDizaji, A. Jafari, and M. de la Guardia. (2017). Early detection of contamination and defect in foodstuffs by electronic nose: A review, TrAC - Trends Anal. Chem., vol. 97, pp. 257-271, doi: 10.1016/j.trac.2017.09.014.

[42] M. Nurjuliana, Y. B. Che Man, D. Mat Hashim, and A. K. S. Mohamed. (2011). Rapid identification of pork for halal authentication using the electronic nose and gas chromatography mass spectrometer with headspace analyzer, Meat Sci., vol. 88, no. 4, pp. 638-644, doi: 10.1016/j.meatsci.2011.02.022.

[43] D. F. Barbin, S. M. Mastelini, S. Barbon, G. F. C. Campos, A. P. A. C. Barbon, and M. Shimokomaki. (2016). Digital image analyses as an alternative tool for chicken quality assessment, Biosyst. Eng., vol. 144, pp. 85-93, doi: 10.1016/j.biosystemseng.2016.01.015.

[44] B. Zhang, et al. (2015). Computer vision detection of defective apples using automatic lightness correction and weighted RVM classifier, J. Food Eng., vol. 146, pp. 143-151, doi: 10.1016/j.jfoodeng.2014.08.024.

[45] A. Girolami, F. Napolitano, D. Faraone, and A. Braghieri. (2013). Measurement of meat color using a computer vision system, Meat Sci., vol. 93, no. 1, pp. 111-118, doi: 10.1016/j.meatsci.2012.08.010.

[46] A. Taheri-Garavand, S. Fatahi, F. Shahbazi, and M. de la Guardia. (2019). A nondestructive intelligent approach to real-time evaluation of chicken meat freshness based on computer vision technique, J. Food Process Eng., vol. 42, no. 4, pp. 1-10, doi: 10.1111/jfpe.13039. 
[47] C. Ruedt, M. Gibis, and J. Weiss. (2020). Quantification of surface iridescence in meat products by digital image analysis, Meat Sci., vol. 163, no. July 2019, p. 108064, doi: 10.1016/j.meatsci.2020.108064.

[48] S. Cubero, N. Aleixos, E. Moltó, J. Gómez-Sanchis, and J. Blasco. (2011). Advances in Machine Vision Applications for Automatic Inspection and Quality Evaluation of Fruits and Vegetables, Food Bioprocess Technol., vol. 4, no. 4, pp. 487-504, doi: 10.1007/s11947-010-0411-8.

[49] P. Zapotoczny, P. M. Szczypiński, and T. Daszkiewicz. (2016). Evaluation of the quality of cold meats by computer-assisted image analysis, LWT-Food Sci. Technol., vol. 67, pp. 37-49, doi: 10.1016/j.lwt.2015.11.042.

[50] A. Przybylak, et al. (2015). Marbling classification of lambs carcasses with the artificial neural image analysis, Seventh Int. Conf. Digit. Image Process. (ICDIP 2015), vol. 9631, no. p. 963113, 2015, doi: 10.1117/12.2197027.

[51] W. Wang, Y. Peng, H. Sun, X. Zheng, and W. Wei. (2018). Real-time inspection of pork quality attributes using dual-band spectroscopy, J. Food Eng., vol. 237, pp. 103-109, doi: 10.1016/j.jfoodeng.2018.05.022.

[52] N. Teimouri, M. Omid, K. Mollazade, H. Mousazadeh, R. Alimardani, and H. Karstoft. (2018). On-line separation and sorting of chicken portions using a robust vision-based intelligent modelling approach, Biosyst. Eng., vol. 167, pp. 8-20, doi: 10.1016/j.biosystemseng.2017.12.009.

[53] A. Y. Khaled, S. Abd Aziz, S. K. Bejo, N. M. Nawi, I. A. Seman, and D. I. Onwude. (2018). Early detection of diseases in plant tissue using spectroscopy-applications and limitations, Appl. Spectrosc. Rev., vol. 53, no. 1, pp. 36-64, doi: 10.1080/05704928.2017.1352510.

[54] Y. Fang and R. P. Ramasamy. (2015). Current and prospective methods for plant disease detection, Biosensors, vol. 5, no. 3, pp. 537-561, doi: 10.3390/bios5030537.

[55] M. Mancini, et al. (2020). “Application of the non-destructive NIR technique for the evaluation of strawberry fruits quality parameters, Foods, vol. 9, no. 4, 2020, doi: 10.3390/foods9040441.

[56] S. Barbon, A. P. A. Da Costa Barbon, R. G. Mantovani, and D. F. Barbin. (2018). Machine Learning Applied to Near-Infrared Spectra for Chicken Meat Classification, J. Spectrosc., vol. 2018, doi: 10.1155/2018/8949741.

[57] S. Savoia, et al. (2020). Prediction of meat quality traits in the abattoir using portable and hand-held near-infrared spectrometers, Meat Sci., vol. 161, p. 108017, doi: 10.1016/j.meatsci.2019.108017.

[58] N. Prieto, R. Roehe, P. Lavín, G. Batten, and S. Andrés. (2009). Application of near infrared reflectance spectroscopy to predict meat and meat products quality: A review, Meat Sci., vol. 83, no. 2, pp. 175-186, doi: 10.1016/j.meatsci.2009.04.016.

[59] A. Rady and A. A. Adedeji. (2020). Application of Hyperspectral Imaging and Machine Learning Methods to Detect and Quantify Adulterants in Minced Meats.

[60] A. Sahar, et al. (2019). Online prediction of physico-chemical quality attributes of beef using visible-near-infrared spectroscopy and chemometrics, Foods, vol. 8, no. 11, pp. 1-12, doi: 10.3390/foods8110525.

[61] M. de Nadai Bonin, et al. (2019). Predicting the shear value and intramuscular fat in meat from Nellore cattle using Vis-NIR spectroscopy, Meat Sci., vol. 163, no. p. 108077, 2020, doi: 10.1016/j.meatsci.2020.108077.

[62] C. Shi, J. Qian, W. Zhu, H. Liu, S. Han, and X. Yang. (2019). Nondestructive determination of freshness indicators for tilapia fillets stored at various temperatures by hyperspectral imaging coupled with RBF neural networks, Food Chem., vol. 275, pp. 497-503, doi: 10.1016/j.foodchem.2018.09.092.

[63] J. H. Cheng, B. Nicolai, and D. W. Sun. (2017). Hyperspectral imaging with multivariate analysis for technological parameters prediction and classification of muscle foods: A review, Meat Sci., vol. 123, pp. 182-191, doi: 10.1016/j.meatsci.2016.09.017.

[64] P. Oliveri, et al. (2014). Partial least squares density modeling (PLS-DM) - A new class-modeling strategy applied to the authentication of olives in brine by near-infrared spectroscopy, Anal. Chim. Acta, vol. 851, no. C, pp. 30-36, doi: 10.1016/j.aca.2014.09.013.

[65] C. H. Feng, Y. Makino, S. Oshita, and J. F. García Martín. (2018). Hyperspectral imaging and multispectral imaging as the novel techniques for detecting defects in raw and processed meat products: Current state-of-the-art research advances, Food Control, vol. 84, pp. 165-176, doi: 10.1016/j.foodcont.2017.07.013.

[66] G. Konda Naganathan, et al. (2016). Three dimensional chemometric analyses of hyperspectral images for beef tenderness forecasting, vol. 169. Elsevier Ltd.

[67] F. Tao and Y. Peng. (2015). A Nondestructive Method for Prediction of Total Viable Count in Pork Meat by Hyperspectral Scattering Imaging, Food Bioprocess Technol., vol. 8, no. 1, pp. 17-30, doi: 10.1007/s11947-014-1374-y.

[68] U. Siripatrawan. (2018). Hyperspectral imaging for rapid evaluation and visualization of quality deterioration index of vacuum packaged dry-cured sausages, Sensors Actuators, B Chem., vol. 254, pp. 1025-1032, doi: 10.1016/j.snb.2017.07.006.

[69] U. Khulal, J. Zhao, W. Hu, and Q. Chen. (2017). Intelligent evaluation of total volatile basic nitrogen (TVB-N) content in chicken meat by an improved multiple level data fusion model, Sensors Actuators, B Chem., vol. 238, pp. 337-345, doi: 10.1016/j.snb.2016.07.074.

[70] J. Xinhua, X. Heru, Z. Lina, G. Xiaojing, W. Guodong, and B. Jie. (2018). Nondestructive detection of chilled mutton freshness based on multi-label information fusion and adaptive BP neural network, Comput. Electron. Agric., vol. 155, no. February, pp. 371-377, doi: 10.1016/j.compag.2018.10.019.

[71] H. Jiang, S. C. Yoon, H. Zhuang, W. Wang, K. C. Lawrence, and Y. Yang. (2017). Tenderness classification of fresh broiler breast fillets using visible and near-infrared hyperspectral imaging, Meat Sci., vol. 139, pp. 82-90, 2018, doi: 10.1016/j.meatsci.2018.01.013.

[72] F. Ma, H. Qin, C. Zhou, X. Wang, C. Chen, and L. Zheng. (2016). Rapid and Non-destructive Detection of Iron Porphyrin Content in Pork Using Multispectral Imaging Approach, Food Anal. Methods, vol. 9, no. 5, pp. 1180-1187, doi: 10.1007/s12161-015-0298-0. 
[73] K. Sendin, M. Manley, and P. J. Williams. (2018). Classification of white maize defects with multispectral imaging, Food Chem., vol. 243, no. June 2017, pp. 311-318, doi: 10.1016/j.foodchem.2017.09.133.

[74] W. H. Su and D. W. Sun. (2018). Multispectral Imaging for Plant Food Quality Analysis and Visualization, Compr. Rev. Food Sci. Food Saf., vol. 17, no. 1, pp. 220-239, doi: 10.1111/1541-4337.12317.

[75] J. Liu, et al. (2016). Rapid and non-destructive identification of water-injected beef samples using multispectral imaging analysis, Food Chem., vol. 190, pp. 938-943, doi: 10.1016/j.foodchem.2015.06.056.

[76] A. Alshejari and V. S. Kodogiannis. (2017). An intelligent decision support system for the detection of meat spoilage using multispectral images, Neural Comput. Appl., vol. 28, no. 12, pp. 3903-3920, doi: 10.1007/s00521-016-2296-6.

[77] L. Estelles-Lopez, et al. (2017). An automated ranking platform for machine learning regression models for meat spoilage prediction using multi-spectral imaging and metabolic profiling, Food Res. Int., vol. 99, pp. 206-215, doi: 10.1016/j.foodres.2017.05.013.

[78] A. I. Ropodi, E. Z. Panagou, and G. J. E. Nychas. (2017). Rapid detection of frozen-then-thawed minced beef using multispectral imaging and Fourier transform infrared spectroscopy, Meat Sci., vol. 135, pp. 142-147, 2018, doi: 10.1016/j.meatsci.2017.09.016.

[79] E. D. Spyrelli, O. Ozcan, F. Mohareb, E. Z. Panagou, and G. J. E. Nychas. (2021). Spoilage assessment of chicken breast fillets by means of fourier transform infrared spectroscopy and multispectral image analysis, Curr. Res. Food Sci., vol. 4, no. September 2020, pp. 121-131, doi: 10.1016/j.crfs.2021.02.007.

[80] W. Wang, et al. (2021). A rapid and non-destructive approach to identify bone fragments embedded in lean pork slices based on multispectral imaging and chemometrics, Infrared Phys. Technol., vol. 113, no. November, p. 103575, doi: 10.1016/j.infrared.2020.103575. 